\title{
Multi Objective Optimization of a Quarter Car Model Fitted with an MR-Damper
}

\author{
[Mohamed Abdelnaeem, Basyouny Elsouhily, Hassan Elgamal]
}

\begin{abstract}
In this paper, an MR-damper fitted to a non-linear quarter car model to obtain the optimum voltage required to handle the MR-damper during the vehicle passing over a bump. Macpherson strut suspension system is implemented for the study. The optimum voltage was obtained depending on ride comfort which was the vertical vehicle RMS acceleration and displacement. The analysis was done by using a genetic algorithm in MATLAB/SIMULINK software. GA is implemented to minimize both the vertical RMS acceleration and displacement of the sprung mass. The results are compared to the passive suspension system. The RMS acceleration is reduced by $71 \%$ and $11 \%$ at velocities of 10 and $70 \mathrm{~km} / \mathrm{hr}$ respectively while the displacement is reduced by $36.6 \%$ and $40 \%$ at the same velocities after the transient period. A pareto front was obtained at different vehicle velocities to demonstrate the effect of vehicle velocity on vehicle vertical acceleration and displacement and gives more flexibility to choose optimum solution as the designer requirement's.
\end{abstract}

Keywords - Macpherson, genetic algorithm, Multi Objective Optimization, MR-damper, pareto front.

\section{I- Introduction}

A car suspension system is the mechanism that isolates the vehicle chasses from the vibrations due to road roughness and bumps. Suspension system consists of springs, dampers and linkages that connect a vehicle chasses to its wheels.

T.A.. Mohamed Abdelnaeem

Faculty of Engineering, Alexandria University

Egypt

Dr. Basyouny Elsouhily

Faculty of Engineering, Alexandria University

Egypt

Prof, Hassan Elgamal

Faculty of Engineering, Alexandria University Egypt
A passive suspension has the ability to absorb energy through a spring and to dissipate it through the damper. Its Parameters are generally fixed, being chosen to achieve a good suspension system, compromise between road handling and ride comfort. Agharkakli, et al [1], applied linear quadratic control technique is to active suspension system of a two degree of freedom quarter car model to improve the ride comfort and road holding. The results proved that, linear quadratic control technique better than passive one. Baumal, et al [2], constructed a five degree of freedom half car model with driver seat and used the genetic algorithm technique to minimize the passenger's seat vertical acceleration as an objective function by using suspension working space and road holding as a constraints. The optimized active design gives better results from the optimized passive one.

Zaidee [3], presented a linear quarter car two degree of freedom model and used a skyhook control system to track the control force of a hydraulic actuator of the active suspension system. His results shows that the inner loop controller is able to track well the target force ranging from sinusoidal, square, sawtooth and step functions of target force. The outer loop controller also showed better results in of vehicle acceleration, displacement and tire deformation, and spring deflection as compared to the passive suspension system. Basari, et al [4], was studied a quarter car nonlinear active suspension system taking into consideration the arm rotational motion with a backstepping control theory. The results were showed that the backstepping control scheme was effectively attenuating the disturbances as compared to LQR controller and passive suspension system. Burqi, et al [5], constructed one and two degree of freedom models using MATLAB software to compared the results of the two models at different road inputs. The vertical displacement and vertical velocity of sprung and unsprung masses were the output of the two models. Sinusoidal and white 
noise road excitations were used to check the models. The results showed that, after the road excitation take place for about one second, sprung mass was arrived to stability faster than the unsprung mass by half second.

Abdelsalam [6], Constructed a two degree of freedom quarter car model in a lab, then applied a several road inputs to compare its results with a simulated one on MATLAB software. The conclusions of compared results were, the measured and simulated data were sufficiently accurate, the model allowed the designer to test the performance of any parameter in vehicle. El-kafay, et al [7], modeled and simulated a two degree of freedom linear model fitted with an MRdamper in MATLAB/SIMULINK software. Sliding mode control was used to force the MR damper to follow the dynamics of ideal sky-hock model. The results showed that the controllable MR-damper has a better road holding compared to passive and active systems. Ali [8], his work was to simulate a quarter car linear model with modified skyhook controller for active suspension system. The results showed that, the active suspension system provides improvements in the ride comfort and road handling compare with the passive suspension system. The behavior of active suspension system with modified skyhook controller is better than active suspension system with skyhook controller. Sanchez, et al [9], their work is to predict the unknown dynamics in the system under analysis by an application that allows to design a nonlinear observer identifier. A quarter-car linear suspension system was modeled. the results were motivated to continue to next step which is the control of half car. Mitra, et al[10], construct a two degree of freedom quarter car linear model fitted with a driver model to increase the ride comfort by using the GA to find the optimized values of suspension spring stiffness, damping coefficient, sprung mass, unsprung mass and tire stiffness. The ride comfort was improved by $13.3 \%$ compared to the passive model before optimization.

Gadhvi, et al[11], used three different methods in multi objective optimization of a half car linear model with five degree of freedom to find the optimized values of front and rear spring stiffness and damping coefficient and the spring stiffness and damping coefficient of the driver seat. He found the pareto front graph which was a relation between the objective functions. Kumar and Vijayarangan[12], developed an active suspension for driver vehicle by constructing a controller using linear quadratic optimal control theory. Two methods were used to apply them on a three degree of freedom quarter car model. Finally, the active suspension system has better ride comfort and road holding, the RMS passenger acceleration has reduced by $54.23 \%$ for conventional method system and by $93.88 \%$ for active acceleration dependent method compared to passive one, and $37.5 \%$ improvement in suspension travel. Bhargav Gadhvi and Vimal Savsani[13], used the teaching-learning based optimization algorithm to solve a quarter car linear model and compared the results with the genetic algorithm technique. The results showed an improvements of sprung mass acceleration and tire displacement by $26.03 \%$ and $23.7 \%$ respectively in teaching-learning based optimization algorithm method, and improvements of $22.3 \%$ and $18.52 \%$ in genetic algorithm technique.

Mehbod, et al[14], made a comparison between active and passive suspensions for seven degree of freedom full car model. The results showed an improvements, the body displacement was reduced from $40 \mathrm{~mm}$ to $15 \mathrm{~mm}$, pitch angle was reduced by $69.23 \%$, and the wheel displacement was improved by $73.3 \%$. Abbas, et al[15], studied a half car model with a driver and its seat to reduce the human body vibration by utilizing genetic multi objective optimization technique. For validation, the results of optimization compared with passive one. The peak acceleration and displacement of the driver were reduced by $85 \%, 86.22 \%$ and $85.32 \%$ were the reduction in peak acceleration and displacement of the driver seat.

\section{II- Mathematical modeling of non-linear suspension system}

The suspension system can be represented with two degree of freedom model. The movement that has been taken into consideration in designing the linear suspension system is the vertical movement of car body and the vertical movement of wheel. The 
dynamic model of a suspension system can be represented by Fig.(1).[8,9]

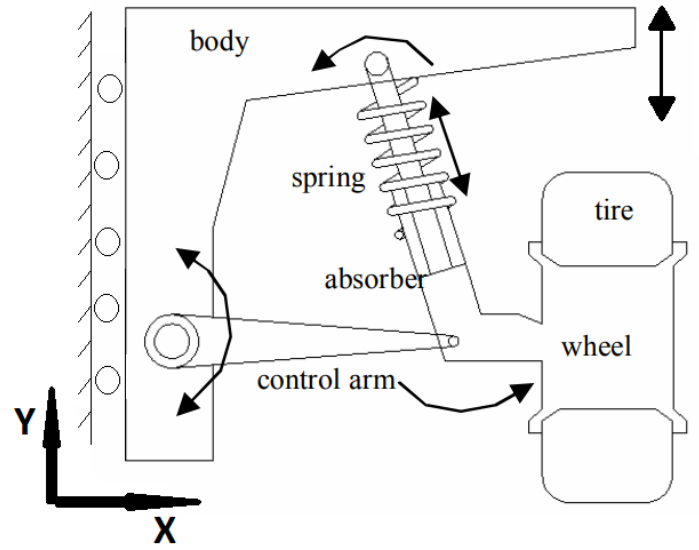

Figure 1. A schematic diagram of a Machperson suspension system for quarter car model

This model admits the rotational movement of the wheel and also the rotational movement of the car body. As these two rotational movements is taken into consideration, the suspension system will become nonlinear. Besides these two movements, the vertical movement of the car body and the suspension movement will be considered too. This will make the model of the suspension system become four degree of freedom. If the joint between the control arm and the car body is assumed to be a pin joint and the mass of the control arm is neglected, then the degree of freedom is becomes two degree of freedom [4].

\section{A. Non-linear Equations of Passive Model}

Fig. 2 shows the generalized coordinates of the quarter car model. $y_{1}$ is the vertical displacement of the sprung mass, $\theta$ describes the angular motion of the control arm, and $y_{R}$ is the road excitation.

By using the Newton's second law, the equations of motion can be obtained.

For the two generalized coordinates $y_{1}$ and $\theta$, the equations of motion are described in (1)and (2).

The calculations is based on car parameter listed in table (1)

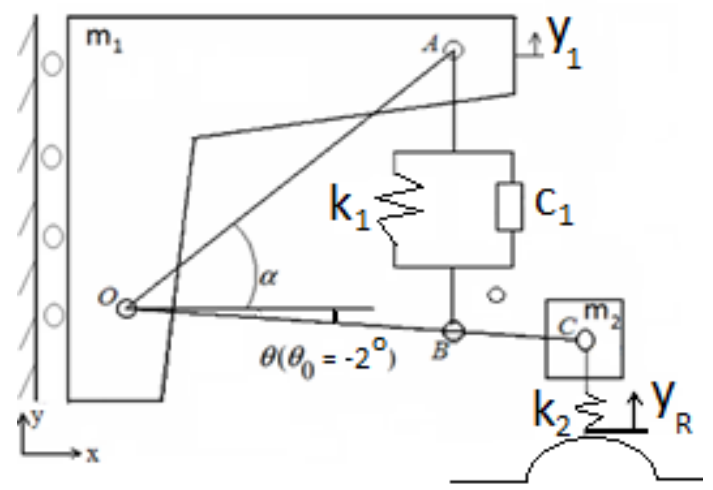

Figure 2. A schematic diagram of a Macpherson suspension system for a passive system

$$
\begin{aligned}
& k_{1} * \Delta l * l_{b} *[\cos \left.\left(\varnothing-\left(\theta-\theta_{o}\right)\right)\right]+c_{1} * \dot{\Delta l} \\
& * l_{b} *\left[\cos \left(\varnothing-\left(\theta-\theta_{o}\right)\right)\right] \\
&+k_{2} * l_{c} * y_{1} * \cos \left(\theta-\theta_{o}\right) \\
&+0.5 * k_{2} * l_{c}{ }^{2} \\
& * \sin 2\left(\theta-\theta_{o}\right)+k_{2} * l_{c}{ }^{2} \\
& * \cos \left(\theta-\theta_{o}\right) * \sin \left(\theta_{o}\right) \\
&+m_{2} * l_{c} * \ddot{y}_{1} \\
& * \cos \left(\theta-\theta_{o}\right)+m_{2} * l_{c}{ }^{2} * \ddot{\theta} \\
&=y_{R} * k_{2} * l_{c} * \cos \left(\theta-\theta_{o}\right) \\
&\left(m_{1+} m_{2}\right) * \ddot{y}_{1}- m_{2} * l_{c} * \dot{\theta}^{2} * \sin \left(\theta-\theta_{o}\right)+ \\
& m_{2} * l_{c} * \ddot{\theta} * \cos \left(\theta-\theta_{o}\right)+k_{2} *\left(y_{1}+l_{c} *\right. \\
&\left.\sin \left(\theta-\theta_{o}\right)+l_{c} * \sin \left(\theta_{o}\right)\right)=k_{2} * y_{R}
\end{aligned}
$$

TABLE 1. Passive Model Constants. [6]

\begin{tabular}{|c|c|}
\hline$m_{1}$ : Sprung Mass & $200 \mathrm{~kg}$ \\
\hline$m_{2}:$ Unsprung Mass & $36 \mathrm{~kg}$ \\
\hline$k_{1}:$ Suspension Spring Constant & $17658 \mathrm{~N} / \mathrm{m}$ \\
\hline$k_{2}:$ Tire Spring Constant & $119921 \mathrm{~N} / \mathrm{m}$ \\
\hline$c_{1}:$ Suspension Damping Constants & $37500 \mathrm{~N} . \mathrm{S} / \mathrm{m}$ \\
\hline length $O B=l_{b}$ & $0.34 \mathrm{~m}$ \\
\hline length OC $=l_{c}$ & $0.37 \mathrm{~m}$ \\
\hline length OA $=l_{a}$ & $0.66 \mathrm{~m}$ \\
\hline$\alpha:$ Constant Angle from Geometry & $76^{\circ}$ \\
\hline$\theta_{o}:$ Initial Angular Position & $-2^{\circ}$ \\
\hline
\end{tabular}




\section{B. Non-linear Equations of Semi- Active Model}

Fig. 3 shows the quarter car model fitted with MRdamper. By using the Newton's second law, the equations of motion can be obtained (3) and (4).

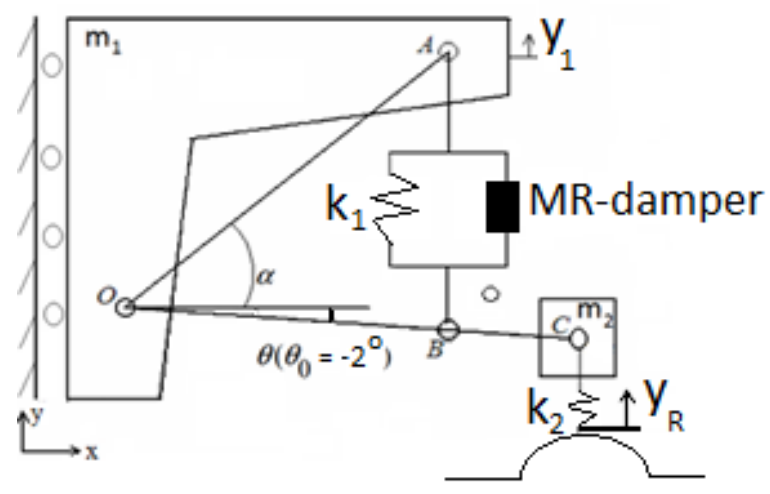

Figure 3. A schematic diagram of a Macpherson suspension system for a semi active system

$F_{d} * l_{b} *\left[\cos \left(\varnothing-\left(\theta-\theta_{o}\right)\right)\right]+k_{1} * \Delta l * l_{b} *$ $\left[\cos \left(\varnothing-\left(\theta-\theta_{o}\right)\right)\right]+k_{2} * l_{c} * y_{1} *$ $\cos \left(\theta-\theta_{o}\right)+0.5 * k_{2} * l_{c}^{2} * \sin 2\left(\theta-\theta_{o}\right)+$ $k_{2} * l_{c}{ }^{2} * \cos \left(\theta-\theta_{o}\right) * \sin \left(\theta_{o}\right)+m_{2} * l_{c} *$ $\ddot{\theta}_{1} * \cos \left(\theta-\theta_{o}\right)+m_{2} * l_{c}{ }^{2} * \ddot{\theta}=y_{R} * k_{2} *$ $l_{c} * \cos \left(\theta-\theta_{o}\right)$

$$
\left(m_{1+} m_{2}\right) * \ddot{y}_{1}-m_{2} * l_{c} * \dot{\theta}^{2} * \sin \left(\theta-\theta_{o}\right)
$$$$
+m_{2} * l_{c} * \ddot{\theta} * \cos \left(\theta-\theta_{o}\right)+k_{2}
$$$$
*\left(y_{1}+l_{c} * \sin \left(\theta-\theta_{o}\right)+l_{c} * \sin \left(\theta_{o}\right)\right)
$$$$
=k_{2} y_{R}
$$

Where $F_{d}$ is the MR damper force.

The model of this study is the Spencer model (see Fig. (4)) operated in valve mode with a mono tube type. The governing equations of this model are:[7]

$$
\begin{aligned}
& F_{d}=C_{1} \dot{y}+K_{1}\left(x-x_{0}\right) \\
& \dot{y}=\frac{1}{C_{1}+C_{0}}\left[\alpha z+K_{0}(x-y)+C_{0} \dot{x}\right] \\
& \dot{z}=-\gamma|\dot{x}-\dot{y}| z|z|^{n-1}-\beta(\dot{x}-\dot{y})|z|^{n}+A(\dot{x}-\dot{y}) \\
& \alpha=\alpha_{a}+\alpha_{b} u \\
& C_{0}=C_{0 a}+C_{0 b} u \\
& C_{1}=C_{1 a}+C_{1 b} u
\end{aligned}
$$

Where $\mathrm{u}$ is given by the following differential equation: $\dot{u}=\eta(u-v)$

$\mathbf{v}$ is the voltage applied to the damper and $\boldsymbol{\eta}$ is a constant governing the rate of change of mag-netic field to reach the equilibrium of the MR fluid. The

\begin{tabular}{|c|c|}
\hline$C_{0 a}=784 \quad \mathrm{~N} \mathrm{~s} / m$ & $C_{0 b}=1803 \mathrm{~N} \mathrm{~s} / \mathrm{V} m$ \\
\hline$C_{1 a}=14649 \mathrm{~N} \mathrm{~s} / m$ & $C_{1 b}=34622 \mathrm{~N} \mathrm{~s} / \mathrm{V} m$ \\
\hline$K_{0}=3610 \quad \mathrm{~N} / \mathrm{m}$ & $K_{1}=840 \quad \mathrm{~N} / m$ \\
\hline$\alpha_{a}=12441 \quad \mathrm{~N} / m$ & $\alpha_{b}=38430 \mathrm{~N} / \mathrm{V} m$ \\
\hline$\gamma=136320 \mathrm{~m}^{-2}$ & $\beta=2059020 \mathrm{~m}^{-2}$ \\
\hline$x_{0}=0.0908$ & $\eta=190$ \\
\hline $\mathrm{A}=58$ & $\mathrm{n}=2$ \\
\hline
\end{tabular}
values of the MR damper parameters are listed in table (2).

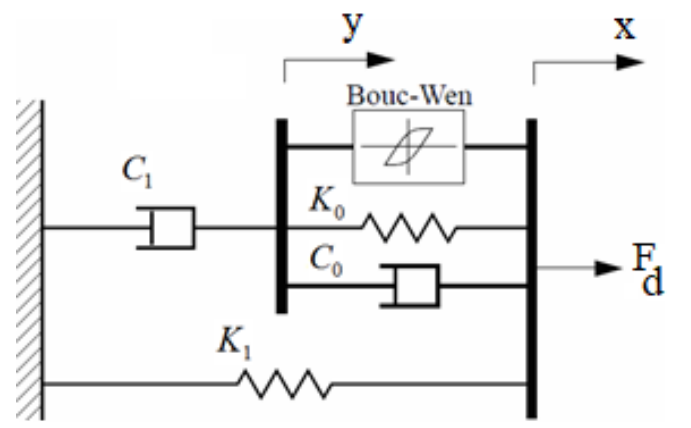

Figure 4. Spencer MR damper model of the Present study.

Table (2) Spencer MR damper parameters.[7]

\section{III- Road excitation}

The road disturbance is assumed to be a single bump modeled as half sine wave with a bump height of 0.1 $\mathrm{m}$ and a wave length of $1 \mathrm{~m}$ with different frequencies due to the vehicle velocities.[1-3,13-15]

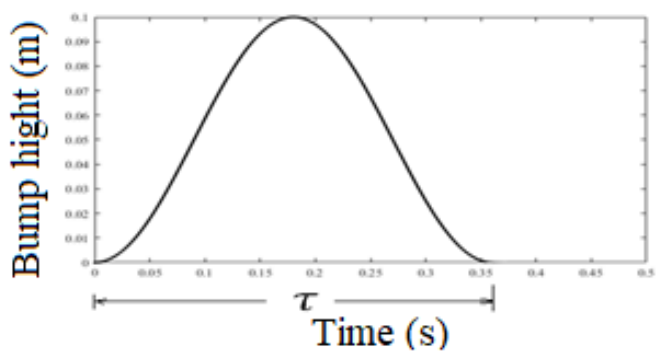

Figure 5. Road profile. 


$$
y_{R}=\left\{\begin{array}{cc}
\frac{a}{2} *[1-\cos (\omega * t)] & \text { for } 0 \leq t \leq \tau \\
0.0 & \text { for } \tau \geq t \geq T
\end{array}\right.
$$

Where $\boldsymbol{a}$ is the bump height of $0.1 \mathrm{~m}, \boldsymbol{\omega}$ is the bump frequency and its value is due to the vehicle velocity, $\mathbf{T}$ is the simulation time of $2 \mathrm{~s}$, and $\boldsymbol{\tau}$ is the period.

\section{IV- Multi objective optimization}

The performance characteristics which are of most interest when designing the vehicle suspension are passenger ride comfort, road holding, passenger vertical displacement and suspension travel. The passenger ride comfort is related to passenger acceleration, suspension travel is related to relative distance between the un-sprung mass and sprung mass and road handling is related to the tire displacement.[2,10-12]

The vehicle semi active suspension system has to fulfill some conflicting criterion such as minimum RMS sprung mass acceleration, passenger vertical displacement which was the most important characteristics. GA based optimization technique is implemented to find the optimum value of MR damper voltage. All simulations are performed using MATLAB / SIMULINK software. To minimize the two objective functions we use the MR damper voltage as a decision variable.

The formulation of optimization problem (two objectives)

\section{f_(obj 1)=Minimize $(\mid$ RMS acceleration $\mid)$ \\ f_(obj 2)=Minimize( vertical displacement $)$}

The optimization program was done on the RMS acceleration and displacement by dividing each curve to twenty equal sections. So, the decision variables are twenty. In each section we take the values at the start and the end of RMS acceleration and displacement to minimize them to find the suitable voltage of the MR damper to manage the bump and let the passenger fell comfort. After the optimization program was terminated we get 72 points which are the optimum values of RMS acceleration and displacement. The pareto front curve was drawn between the two objectives and has the concave portion. The trade-off between RMS acceleration and displacement can be clearly observed in Figure (10).

\section{V- Results and discussion}

\section{A. For passive model}

Fig. (6) illustrates the relation between sprung mass vertical displacement at different vehicle velocities with simulation time. For vehicle speed up to 30 $\mathrm{km} / \mathrm{hr}$ the displacement exceeds $0.1 \mathrm{~m}$ which is the bump height. For velocities of 30 to $70 \mathrm{~km} / \mathrm{hr}$ as the velocity increased the displacement decreased. The conclusion from the figure is as the vehicle speed increased the peak amplitude decreased. So, for a speed range over $30 \mathrm{~km} / \mathrm{hr}$ the passenger feel less displacement from the bump.

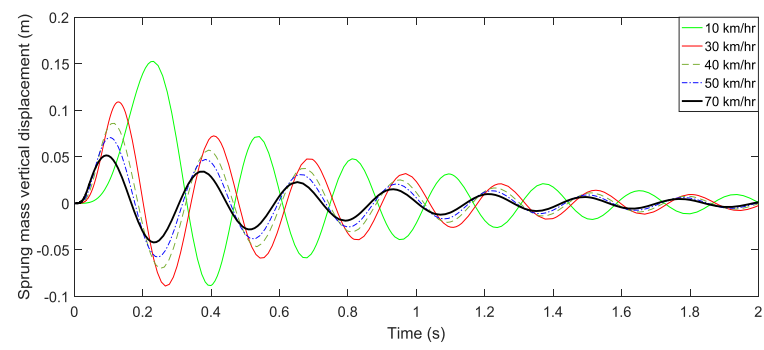

Figure 6. Sprung mass vertical displacement at different vehicle velocities

Fig. (7) shows the effect of vehicle speed on RMS vertical acceleration of the sprung mass with simulation time. The figure shows a transient period of $0.35 \mathrm{~s}$. After the transient period of $0.35 \mathrm{~s}$, as vehicle speed increased the acceleration decreased because the vehicle pass over the bump quickly.

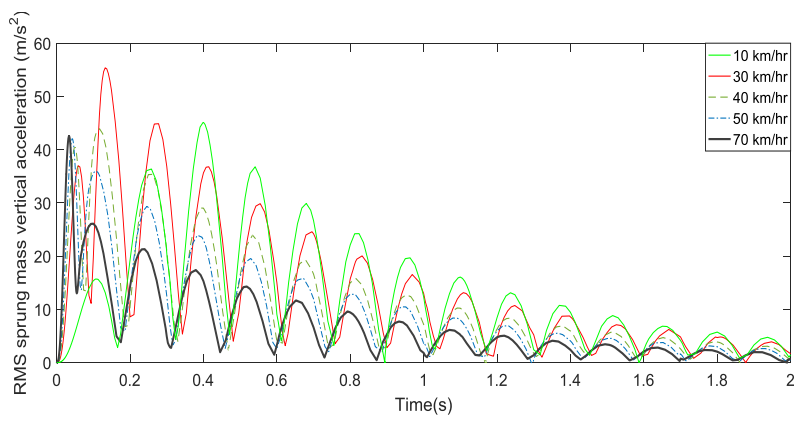

Figure 7. Sprung mass vertical displacement at different vehicle velocities. 


\section{B. For semi-active model}

Fig. (8) illustrates the relation between sprung mass vertical displacement at different vehicle velocities with simulation time. For vehicle speed up to 30 $\mathrm{km} / \mathrm{hr}$ the displacement exceeds $0.1 \mathrm{~m}$ which is the bump height. For velocities of 30 to $70 \mathrm{~km} / \mathrm{hr}$ as the velocity increased the displacement decreased. The conclusion from the figure is as the vehicle speed increased the peak amplitude decreased. So, for a speed range over $30 \mathrm{~km} / \mathrm{hr}$ the passenger feel less displacement from the bump.

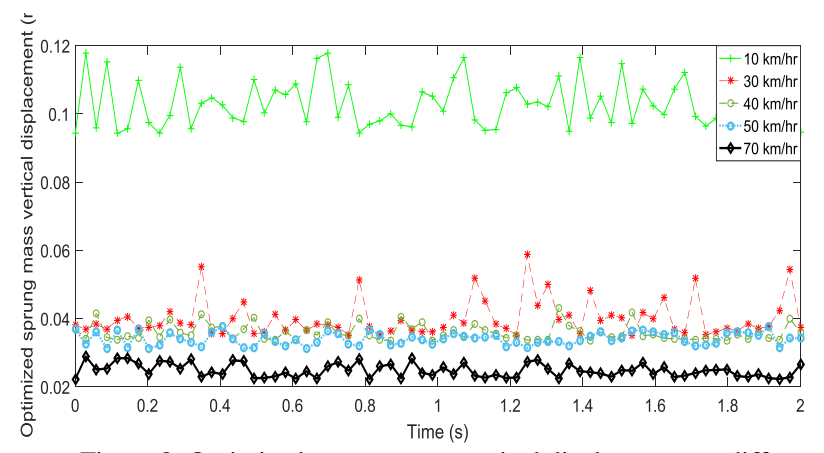

Figure 8. Optimized sprung mass vertical displacement at different vehicle velocities.

Fig. (9) demonstrates the relation between the optimized sprung mass RMS acceleration with time. The present work was done to show the effect of vehicle speed on the ride comfort and passenger vertical displacement. The vehicle velocities were 10 , $30,50,70 \mathrm{~km} / \mathrm{hr}$. The results showed a remarkable behavior of the optimized RMS acceleration at 30 $\mathrm{km} / \mathrm{hr}$ velocity.

By a simplified method the natural frequencies were found to be 4.6 and $35 \mathrm{~km} / \mathrm{hr}$, so it was decided to run the optimization program at a velocity of 40 $\mathrm{km} / \mathrm{hr}$ to check the data obtained from velocity 30 $\mathrm{km} / \mathrm{hr}$. As showed in figure (9) the optimized acceleration of $40 \mathrm{~km} / \mathrm{hr}$ was approximately the same as $30 \mathrm{~km} / \mathrm{hr}$ and that is was due to the second natural frequency of the system. As the system run at velocities over $40 \mathrm{~km} / \mathrm{hr}$ away from the natural frequency, the RMS acceleration decreased.

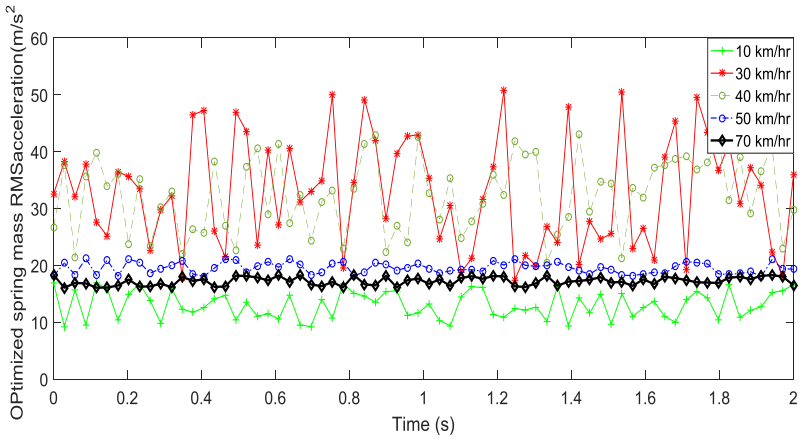

Figure 9. Optimized sprung mass RMS acceleration at different vehicle velocities.

\section{Pareto front}

Figure (10) contains the RMS acceleration and vertical displacement of the sprung mass which are the two objective functions. There are seventy two optimized points on pareto front chart. The pareto front curve was drawn between the two objectives and has the concave portion. Each point on pareto front graph has a voltage history, so the designer has to decide which parameter to be preferred more as per utility of vehicle.

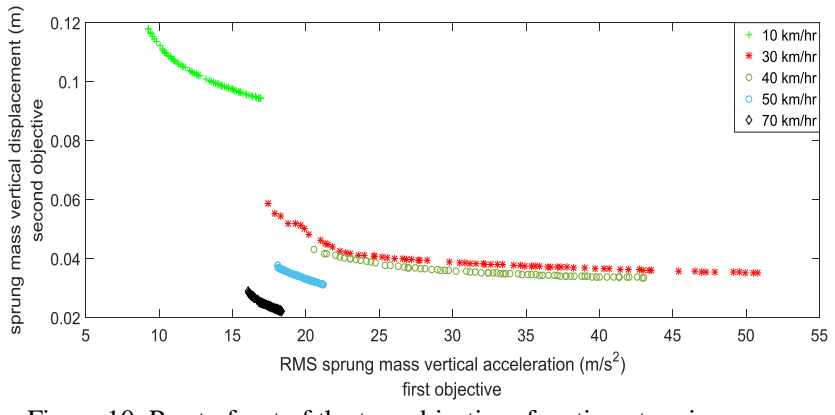

Figure 10. Pareto front of the two objectives function at various vehicle velocities.

\section{VI- Conclusion}

A quarter car suspension systems fitted with MR damper has been modeled, investigated and compared with passive suspension system. The performances of the car suspension system under road excitation has been done through MATLAB/SIMULINK software. Based on the results obtained, the optimized displacement is improved by $36.6 \%$ and $40 \%$ at velocities of 10 and $70 \mathrm{~km} / \mathrm{hr}$ respectively while the RMS acceleration improved by $71 \%$ and $11 \%$ at same previous velocities after the transient period of $0.35 \mathrm{~s}$. 


\section{References}

[1] A. Agharkakli, G. Shafiei Sabet, A. Barouz, "Simulation , and analysis of passive and active suspension system using quarter car model for different road profile", International Journal of Engineering Trends and Technology, Vol. 3, pp 636-644, 2012.

[2] A.E Baumal, J.J. McPhee, P.H. Calamai, “ Apllication of genetic algorithms to design optimization of an active vehicle suspension system", Elsavier, Vol. 163, pp. 87-94, .1998.

[3] M. E. B. Zaidee" modeling and simulation of skyhook controller for active suspension system", Faculty of Mechanical Engineering, University Malaysia Pahang, DECEMBER 2010.

[4] A. A. B. Basari, Y. Md. Sam, N. Hamzah, "Nonlinear active suspension system with backstepping control strategy", Second IEEE Conference on Industrial Electronics and Applications, CHINA, 2007.

[5] M. Burqi, R. Likaj, A. Shala, "Simulation of vertical quarter car model with one and two d.o.fs", Scientific Proceedings III International Scientific-Technical Conference "INNOVATIONS",BULGARIA, pp 110-112, 2017.

[6] A. Abdelsalm, "Modeling and simulation of conventional quarter car suspension system", ALEXANDRIA UNIVERSITY, EGYPT, PHD thesis, 2017.

[7] M. El-Kafafy, S. M. El-Demerdash, A. M. Rabeih, "Automotive ride comfort control using mr fluid damper", scientific research journal, vol. 4, No. 4, pp 179-187, 2012.

[8] M. R. B. Ali , "modeling and simulation of modified skyhook controller for active suspension system", Faculty of Mechanical Engineering, UNIVERSITI MALAYSIA PAHANG, 2010.

[9] E. A. Sanchez, R. A. Franco, A. L. Velazquez, "Nonlinear observer-estimator application: quarter-car suspension system under road disturbances", Vol. 2, NO. 4, pp 193-198, 2013.

[10] A. C. Mitra, G. J. Desai, S. R. Patwardhan, P. H. Shirke, “ optimization of passive vehicle suspension system by genetic algorithm", vol. 144, pp 1158 - 1166, 2016.

[11] B. Gadhvi, V. Savsani, V. Patel, " Multi objective optimization of vehicle passive suspension system using NSGA-II, SPEA2 and PESA-II", Third International Conference on Innovations in Automation and Mechatronics Engineering, ICIAME, INDIA, vol. 23, pp 361-368, 2016.

[12] M. S. Kumar, S. Vijayarangan, "Design of LQR controller for active suspension system", Indian Journal of Engineering and Materials Sciences, vol. 13, pp 173-179, 2006.

[13] B. Gadhvi, V. Savsani, "Passive suspension optimization using teaching learning based optimization and genetic algorithm considering variable speed over a bump", ASME International Mechanical Engineering Congress and Exposition, CANADA, PP 1-7, 2014.

[14] M. R. Mehod, H. Moosavi, A. Karimipour, " Stability analysis for seven d.o.f vehicle model with active and passive suspension system while crossing the speed hump", World Academy of Science, Engineering and Technology, vol. 61, pp 1196-1200, (2012).

[15] W.Abbas, A. Emam, S. Badran, M. Shebl, O. Aboulatta," Optimal seat and suspension design for a half-car with driver model using genetic algorithm", Intelligent Control and Automation, vol. 4, pp 199-205, 2013.
About Authors:

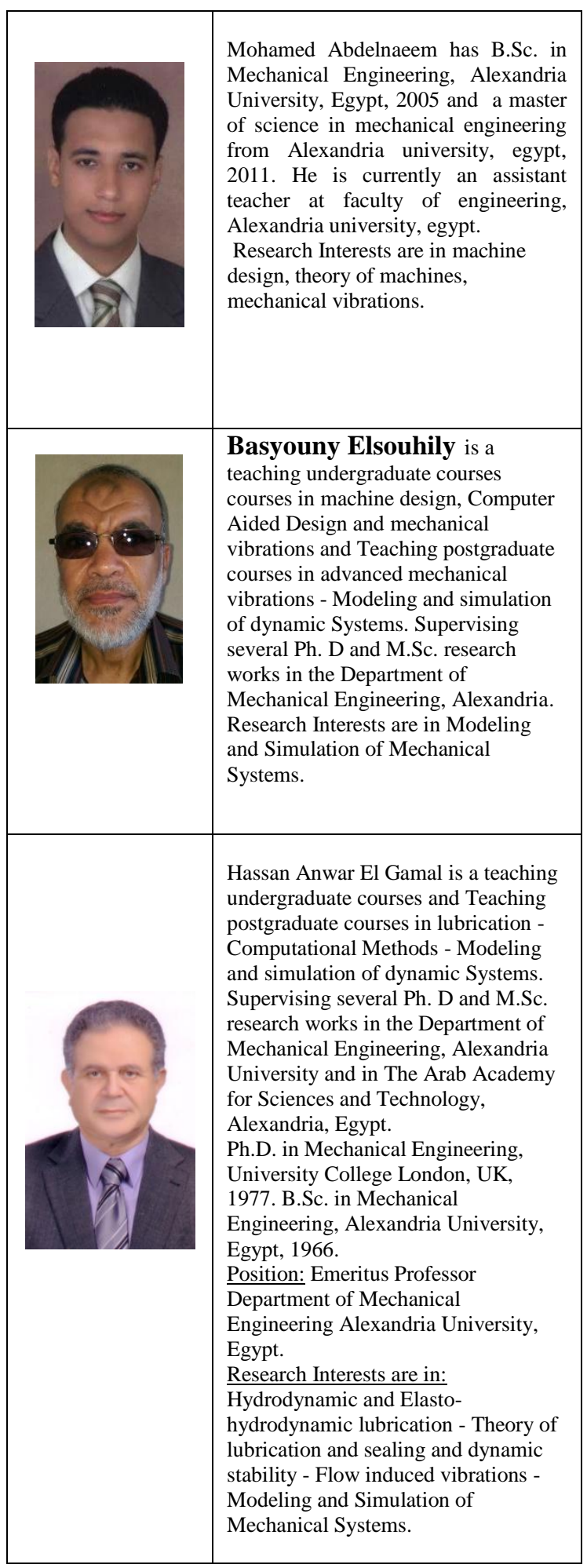

